\title{
Standardization of requirements to operation of buildings and facilities
}

\author{
Alexandr Mamin ${ }^{1, *}$, Emil Kodysh ${ }^{1}$ and Vladimir Bobrov ${ }^{2}$ \\ ${ }^{1}$ JSC «TSNIIpromzdany», Dmitrovskoe shosse, bld.46-2, Moscow, 127238, Russia \\ ${ }^{2}$ Moscow State University of Civil Engineering, Yaroslavskoe shosse, 26, Moscow, 129337, Russia
}

\begin{abstract}
Safe operation, reliability and durability of capital facilities (hereinafter - CF) are becoming more and more topical.

All phases except operation (including all types of maintenance and repairs) and demolition were covered by regulatory requirements, while operation as the longest phase in CF life and the final stage - demolition were not included into regulations until recently. There were industry specific codes for nonproduction and industrial buildings and facilities and documents derived from them, but they were inconsistent, lead time to repair differed even for similar structures and operation conditions and these discrepancies did not allow setting the specific frequency of repairs which resulted in neglected defects and damages shortening the life of buildings and structures or causing accidents.

In 2015, the authors, in team with other experts, developed SP 255.1325800.2016 "Buildings and structures. Rules of operation. Key provisions" (hereinafter - SP 255), setting general requirements to operation of buildings and structures under regular conditions, but the diversity of buildings' functions required the development of numerous codes of practice derived from SP 255 and some of them were drafted in 2016-2018.

Codes of operation practice will (if elaborated) contribute to the reduction of operation and maintenance costs and ensure required safety of capital facilities.
\end{abstract}

\section{Ensuring the operational reliability of buildings and structures}

Safe operation, reliability and durability of capital facilities (hereinafter - CF) are becoming more and more topical. Key requirements to operational safety of buildings and structures are laid down in Federal Laws [1,2], but they are not directly applicable, contain only general standards to be met and do not define particular measures to be taken. Operational safety of the building or structure shall be provided by carrying out maintenance, periodic inspections and (or) monitoring of the state of building structures and engineering systems, including automated monitoring of the technical condition of buildings and structures.

Regulatory requirements to the durability of buildings, structures and their elements are defined by GOST (State Standard) 27751-2014 "Reliability of building structures and

\footnotetext{
* Corresponding author: otozs@yandex.ru
} 
foundation. General provisions" and are aimed to ensure the safety of at all phases of their life. As stated in item 5, part 2 of Article 2 [1] life of a building or a facility means a period of engineering surveys, design, construction, operation and demolition [3]. All phases except operation (including all types of maintenance and repairs) and demolition were covered by regulatory requirements [4], while operation as the longest phase in CF life and the final stage - demolition were not included into regulations until recently. There were industry specific codes for nonproduction and industrial buildings and facilities [5, 6] and documents derived from them [7,8], but they were inconsistent, lead time to repair differed even for similar structures and operation conditions. For example, in [6] the frequency of overhaul for reinforced concrete and concrete foundation under normal operation is 50-60 years, and 40-50 years for rubber stone footing and brick base; while [8] states that this frequency should make 50 years for reinforced concrete and concrete foundation, 40 years for rubber stone footings and 30 years for brick base. The frequency of repairs for reinforced concrete and concrete foundation subject to vibration is 15-20 years in [6] and 25 years in [8]. These discrepancies do not allow setting the specific frequency of repairs which results in neglected defects and damages shortening the life of buildings and structures or causing accidents.

\section{The current state of the regulatory framework for the operation of buildings and structures in the Russian Federation}

In view of the above and following the request of RF Ministry of Construction, the authors, in team with other experts, in 2015 developed SP 255.1325800.2016 "Buildings and structures. Rules of operation. Key provisions" (hereinafter - SP 255 (Construction Rules)) enacted on February 25.2017 and setting general requirements for operation of buildings and structures under regular conditions [9]. After changes of 2011 part 12 of article 48 " Architectural and construction design "[2] is added with point 10.1 according to which the section"Requirements to ensuring safe operation of capital construction projects" should be included in structure of design documentation of capital construction projects. In the text of SP 255 requirements to structure and the contents of this section are given, and in appendices - requirements to structure and the contents "Regulations on ensuring safe operation of the building (construction)" which shall be developed by the owner if concerning capital construction project there is no section of the project documentation establishing requirements to ensuring safe operation. But requirements to buildings of various functionality are so diverse $[10,11,12,13,14]$, that a number of codes of practice had to be derived from SP 255. Codes of practice specific for the operation of multipurpose shopping malls, sports centers, industrial buildings and facilities, medical centers, multicompartment, skyscrapers and other objects were developed in 2016-2018. Operation guidelines [17] were made for utility systems (ventilation and air-conditioning, heating and water supply) [15, 16]. Sets of rules for post earthquake inspection and design of seismometric stations were provided for earthquake prone regions. Rules for demolition and disposal of buildings and facilities were developed to cover the final phase of CF life [19].

Alterations into SP 255 made in 2018 were initiated by Resolution of RF Government \# 743 "Rules of safe operation and maintenance of lifts, lift platforms for disables persons, moving walkways (travolarators) and moving stairs, expect for moving stairs in subways" approved on June 25, 2017 and abolishment of PB (Safety rules) 10-574-03, PB 10-77-94, SO (Industrial Standard) 34.20.514-2005, GOST RP 53780-2010 "Lifts. General safety requirements to design and installation", GOST R 54859-2011 "Buildings and structures. Parameters of natural vibration frequencies", updated and new codes of practice. The code of practice was updated by such new Exhibits as Operative passport, 
Operation log, Form of the acceptance commission report to commission the object after the overhaul. The definitions were clarified together with the classification of operation requirements in view of Article 9 of Federal Law № 384-FZ "Safety requirements under the impact of hazardous natural and (or) man-made events" dated December 30, 2009, and additional requirements to the operation of pipelines were set.

\section{Prospects for further development of the regulatory framework for the operation of buildings and structures in the Russian Federation}

A code of practice is, as a rule, based on research activities and the authors did participate in some of them ("Identification of works and services necessary for operation of capital facilities and required frequency of such works and services", "Monitoring and analysis of construction regulatory documents, containing methods to define the durability of bearing and enclosing structures to prepare proposals for their updating", "Development of methods of classification of building materials, products and structures, and determining the standard terms of their operation", "Surveys of apartment buildings in different climatic regions of the Russian Federation to establish the relationship of the timing of operation of the technical state of facilities and operating conditions"; "Surveys of public buildings in different climatic regions of the Russian Federation to establish the relationship of the timing of operation of the technical state of facilities and operating conditions"; "Conducting surveys of industrial buildings in different climatic regions of the Russian Federation to establish the relationship of the timing of operation of the technical state of facilities and operating conditions", "Surveys of multi-functional highrise buildings in different climatic regions of the Russian Federation to determine the dependence of the service life on the technical condition of objects and operating conditions" etc.). Here below we provide some results of those studies.

Analyses of surveys made by CNIIPZ JSC (Central Research and Experimental Institute for Industrial Buildings and Facilities) and National Research Moscow State University of Civil Engineering proved that significant number of defects and damages result from poor quality of building and construction works and should be eliminated prior to commissioning. It implies the maximum possible involvement of an operator in CF commissioning for the detection and elimination of building and construction defects. But the lack of operator's personnel able to indentify relevant defects, including hidden defects, necessitates the invitation of qualified companies to witness the commissioning of constructed, refurbished or repaired buildings and facilities.

The operational experience shows that scheduling of repairs should be, first of all, based on regular surveys and inspections of structures that provide objective data on the technical state of a facility or its components.

Analysis of CF operation allows to define the deterioration of wearable elements (roof, floors, and joints) and to detect trends in the gradual damage of durable structures, depending on their application or operation. If we reveal the trends in the changes of construction structures and utility lines, we will be able to forecast their service life and frequency of repairs necessary for particular facilities and their components. Therefore complete and timely filling of operation documents is extremely important for the due understanding of finishing materials and $\mathrm{CF}$ elements degradation patterns and for maintenance planning.

The reliability of buildings should be, in general, defined by the design which must ensure the equal reliability of structures, equal term of operation, multiplicity factor for the service life of building structures, materials and elements in view of the whole building 
design service life. However, industrial processes, impact of humidity and rates of defects propagation vary so much that no single document can described them and we believe necessary to add the existing codes of practice with the following:

- SP "Preschool education buildings. Rules of operation";

- SP "Buildings for vocational and higher education. Rules of operation";

- SP "Parking lots. Rules of operation";

- SP "Public performance and entertainment facilities. Rules of operation";

- SP "Swimming pools. Rules of operation"

The above-mentioned codes should ensure:

- classification of capital facilities as per code classes;

- compliance of constructed facilities and process equipment parameters to design or regulated parameters;

- $\quad$ proper conditions for correct functioning of equipment in the facility;

- timely detection and proper identification of defects (faults) in structures;

- timely elimination of defects in such building structures and elements that ensure proper functioning of process equipment;

- timely maintenance of structures;

- due healthy working condition on the site and adjacent area.

Subsurface parts of buildings and facilities are subject to humidity and other aggressive environment which hinders detection of defects. Therefore it would be feasible to make a study on "Operation of subsurface and embedded part of buildings and facilities. Service procedures, supervision, maintenance and repairs for various structures". It is important, as often the waterproofing fails during first years of operation, causing the deterioration of building structures, premature destruction and increased maintenance costs [20, 21].

The main purpose of this study is to analyze the regulatory documents, to sum up experience of scientifically justified maintenance, to define the scope of supervision, service and repair for various subsurface and embedded parts of buildings and structures; to elaborate proposals for updating and drafting of new codes of practice to ensure safe and failure-free operation of structures, to eliminate their premature wear that downgrades safety, initiates unscheduled repair and increases the cost of scheduled maintenance.

This study should result in:

- classification of subsurface and embedded parts of buildings and facilities in view of their operation specifics;

- $\quad$ analysis of domestic and foreign regulations defining requirements to supervision over subsurface and embedded parts of buildings and structures and evaluation criteria;

- $\quad$ specific requirements to operation of subsurface and embedded parts of buildings and facilities;

- proposals on the scope of works and frequency of inspections for subsurface and embedded parts of buildings and facilities based on scientific analysis and pilot on-side inspections ;

- technical assessment criteria for subsurface and embedded parts of buildings and facilities compliance with design documents and regulatory requirements;

- methodology of maintenance, including current repairs and emergency prevention activities derived from the examination of efficiency of available recommendations for subsurface and embedded parts of buildings and facilities servicing;

- requirements and methods of a facility warranty monitoring under a section of design documents "requirements to safe operation of a capital facility";

- requirements to operational monitoring (supervision) and servicing of subsurface and embedded parts of buildings and facilities; definition of operator's functions to monitor the state of subsurface and embedded parts of buildings and facilities. 
The study results can be useful for elaboration of regulatory, technical and administrative documents to guide the operation of subsurface and embedded parts of buildings and facilities and drafting SP "Subsurface parts of buildings and facilities. Rules of operation".

Conclusions:

1.It is necessary to conduct further research to identify specific requirements for the operation of buildings and structures for various functional purposes, as well as their individual parts in different operating conditions.

2. On the basis of these studies should be developed further codes of practice for the operation of buildings and structures. The above-mentioned code of practice can help to reduce the costs of operation, maintenance and repair and ensure the necessary safety of capital facilities for various functional purposes, maintain normal sanitary and hygienic conditions, ensure the required level of safety, maintain compliance of buildings and structures with their functional purpose, reduce the risk of harm to health, property and the environment by improving the reliability and durability of building structures and engineering systems.

3. Special operating manuals should be developed for the various buildings and structures, which will provide specific methods for implementing the requirements specified in the codes of practice.

4. Unique buildings and facilities, as well as cultural heritage sites, should be provided with automated condition monitoring systems.

\section{References}

1. Federal Law 384 FZ "Technical regulations for safety of buildings and facilities", adoped December 30 (2009)

2. Federal Law 190 FZ "City planning Code of the Russian Federation", adopted December 29 (2004)

3. Korotkova D.Yu., Chulkov V.A. Life cycle of a construction object. World of science. Issue 1. Available at: https://mir-nauki.com/PDF/18TMN113.pdf. (2013)

4. Volkov A.A., Telichenko V.I., Leibman M.E. Fundamentals of design, construction and operation for buildings and facilities [e-lectures]: Textbook/ Electron. Text data. Moscow: Moscow State Univercity of Civil Construction. ASV. 492 p. Available at: http://www.iprbookshop.ru/30437.html (2015)

5. VSN-58-88(r) Management and execution of reconstruction, maintenance and repairs (1990)

6. POT RO 14000-004-98 Regulations. Techincal operation of industrial buildings and facilities (1998)

7. Guidelines for technical operation of buildings, facilities, utility systems and devices. FGUP Izvestia Publishing house. Moscow. 276 p. (2017)

8. STO 70238424.27.100.003-2008 CHP buildings and facilities. Operation and maintenance. Rules and requirements. Moscow. 114 p. (2008)

9. Korol E.A. Progress in elaboration of regulatory framework for buildings and facilities operation and updating of educational programs. MSUCC Bulletin 2017. Vol. 12. no. 10 (109), pp 1082-1089. (2017)

10. Gryaznov M.V., Popova M.V., Vlasov A.V., Rimshin V.I., Markov S.V., Sinyutin A.V. Key issues of large-panel buildings operation and their solutions. Natural and technical sciences. no. 9-10 (77), pp. 355-357 (2014) 
11. Kultchitskyi S.V., Tretayk D.V., Galiev M.G., Danilov A.G., Gratchev E.A. Monitoting of technical state of insdustrial buildings with expried service life. Modern science: topical issues of theory and practice. Series: natural and technical sciences. no. 9-10, pp. 37-38 (2015)

12. Samigulin G.F. Safe operation of buildings and facities subject to corrosive environment in petrochemistry and oil-refining. Information and analytical bulletin on mining (scientific and technical journal). no. 2, pp. 113-118. (2015)

13. Fadeeva G.D., Garkin I.N. Solution of problems in the operation of industrial buildings and facilities. Young scientist. no. 12 (71), pp. 120-121. (2014)

14. Sychev O.V., Nechaev R.Yu., Shirkin R.V. Operation of industrial buildings and facilities on a hazardous site. Innovative science. no. 12-2, pp. 144-145. (2015)

15. Starostin V.R., Kulakov K.Yu. Problems in operation of water utility systems and specifics of their diagnostic. Economy and entreprenership. no. 4-2 (81), pp. 910-913. (2017)

16. Yanchenko V.A. Technical operation and reconstruction of utility systems in buldings and facilities. Irkutsk, Irkutsk national research technical university. 154 p. (2016)

17. Burkeev D.O. Improving the efficiency of buildings and thier utility lines operation. Management of economic system: e-scientific journal. no. 11 (105), p. 43. (2017)

18. Skabelina L.I. Safe operation of buildings and facilties in earthquake prone regions. Scientific backround of agro-business and rural areas development under WTO. Papers of internation scientific and practical conference dedicated to 70 years of Volgograd Agriculyural University foundation. pp. 145-147. (2014)

19. Mamin A.N., Kodysh E.N., Bobrov V.V. Development of regulatory documents for operation of buildings and facilities. Industrial and civil construction. no. 6, pp. 24-27. (2018)

20. Shilin A.A. Waterproofing of subsurface and embedded buildings during construation and repairs: monograph. Moscow: MISI-MGSU. 372 p. (2018)

21. Sokova S.D., Kalinin V.M. Improving the reliability of subsurface waterproofing during operation of buildings. Housing construction. no. 7, p. 63. (2015) 